\title{
Dual-function slot antenna integrated with solar cells for the $1.575-\mathrm{GHz}$
}

\section{band}

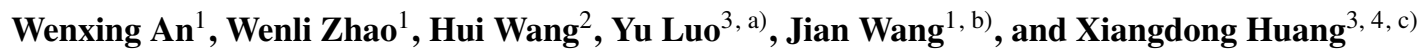

\begin{abstract}
A linearly polarized slot antenna integrated with solar cells is presented. The proposed antenna operates at the center frequency of 1.575 $\mathrm{GHz}$ for the global navigation satellite systems. 40 solar cells are adopted for the radiation structure and 4 slots are formed by these solar cells, which can not only be used for wireless communication but also generate DC energy via the photoelectric effect. The proposed design has achieved a relative bandwidth of $19.9 \%$ from $1.45 \mathrm{GHz}$ to $1.77 \mathrm{GHz}$. Bidirectional radiation performance has been realized and the measured gain at 1.575 $\mathrm{GHz}$ is $6.6 \mathrm{dBi}$

Keywords: slot antenna, solar cell, radiation pattern, dual-function device Classification: Microwave and millimeter-wave devices, circuits, and modules
\end{abstract}

\section{Introduction}

In recent years, the Global Navigation Satellite System has developed rapidly and played an important role in the civil and military areas. To meet the huge application requirements, many different positioning systems have been developed including the Global Positioning System (GPS) from the U. S. A., Global Navigation Satellite System (GNSS) from Russia, Galileo Navigation Satellite System from the European Union, and BeiDou Navigation Satellite System from China. The frequency band near $1.575 \mathrm{GHz}$ has been adopted for many global positioning systems, e. g. the GPS L1 band, Galileo E1 band, and Compass B1-band.

Many RF circuits have been studied and designed for global navigation satellite systems $[1,2,3,4,5,6,7,8]$. As the antenna plays an important role in the RF systems, many different types of antenna have been investigated and reported at $1.575 \mathrm{GHz}$ including planar invertedF antenna (PIFA) [9], U-shaped [10] and meshed [11]

${ }^{1}$ Tianjin Key Laboratory of Imaging and Sensing Microelectronic Technology, School of Microelectronic, Tianjin University, Tianjin 300072, China.

${ }^{2}$ Qingdao Key Laboratory of Marine Information Perception and Transmission, Qingdao Institute of Ocean Engineering of Tianjin University, Qingdao 266235, China.

${ }^{3}$ Joint Laboratory for Ocean Observation and Detection, Qingdao National Laboratory of Marine Science and Technology, Qingdao 266235, China.

${ }^{4}$ Department of Electronic Engineering, Tianjin University, Tianjin 300072, China

a)xdhuang@tju.edu.cn

b)1016204014@tju.edu.cn

c)yluo@tju.edu.cn

DOI: $10.1587 /$ elex.17.20200322

Received September 24, 2020

Accepted October 6, 2020

Publicized October 26, 2020

Copyedited November 10, 2020 patch, spiral [12], substrate-integrated-waveguide [13] and monopole [14] antennas. Although satisfactory performance has been achieved based on the above designs, the antenna can only be used for wireless communications. For the outdoor and spatial autonomous systems, the power supply has become the major concern and it is desired to integrate the solar cell and antenna into one to save the limited space and payload, which can not only be adopted for wireless communication but also generate free DC energy to supply the entire system.

There are already some researches on the integration of $\mathrm{RF}$ antenna and solar cell for the $1.575-\mathrm{GHz}$ band. Slot and dipole antennas have been discussed $[15,16]$. Although satisfactory performances have been realized, the solar cells in these designs are treated as the parasitic structure or reflector instead of the radiator, so the cost and system flexibility are not reduced effectively. Replacing the radiating patch with a single solar cell, an aperture coupled planar antenna was reported in [17]. A monopole antenna integrated with a solar cell for wearable applications was presented in [18]. By cutting certain shapes on the solar cell, a Vivaldi antenna with an end-fire radiation pattern was designed in [19]. To enhance the ability of DC power generation, a solar cell array with 36 solar cells have been used as the radiation structure of the proposed GPS antenna [20, 21, 22]. However, the antenna has a relatively lower gain of $2 \mathrm{~dB}$ due to the influence of the introduced solar cell structure with electrically large size. To achieve both high-gain and satisfactory DC-power-generation performance, novel antenna design integrated with more solar cells is desired with less interaction from each other.

In this letter, a solar-cell slot antenna is proposed for the 1.575-GHz application. 40 solar cells are adopted to replace the traditional copper patch. Four parallel slots are formed by these solar cells and act as the main radiator. A relative bandwidth of $19.9 \%$ has been realized and the target band of $1.575 \mathrm{GHz}$ has been fully covered. Moreover, bidirectional radiation patterns have been obtained with low-level crosspolarization. For this dual-function device, the DC path with a bandstop filter has been introduced to collect DC energy from solar cells.

\section{Antenna structure description}

To integrate the antenna and solar cell, one kind of solar cell is chosen with a detailed structure in Fig. 1. It has a threelayer structure and consists of the gridlines, epitaxial layer, and the copper layer. The epitaxial layer plays an essential 


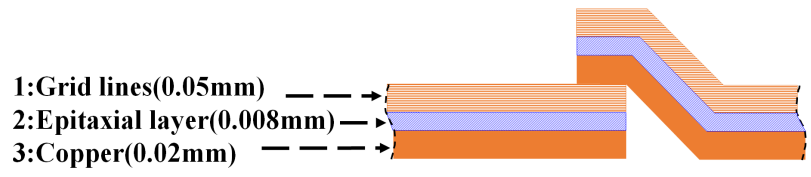

Fig. 1 The multilayer structure of the solar cell and its serial connection of two solar cells.

role, which can generate DC energy via the photoelectric effect. The gridlines and copper act as the negative and positive poles of the solar cell battery. The adopted single solar cell has a size of $20.8 \times 40.8 \mathrm{~mm}^{2}$, which is relatively small compared with the wavelength of $1.575 \mathrm{GHz}$. To realize effective radiation at $1.575 \mathrm{GHz}$, several solar cells are connected in series to form the radiation structure. It is observed in Fig. 1 that the edges of two adjacent solar cells are overlapped with each other along the long side. The gridlines of one solar cell are soldered to the copper layer of the other one.

The geometry of the proposed slot antenna integrated with solar cells is shown in Fig. 2 with the detailed size in Table I. The top radiation structure in Fig. 2(b) is with the lengths from $L$ to $L_{3}$, and the widths from $W$ to $W_{5}$. The feeding strip printed on the bottom has the lengths from $L_{4}$ to $L_{7}$ and the widths from $W_{6}$ to $W_{9}$. The filter has the sizes from $F$ to $F_{5}$. The DC path is with the $L_{8}, L_{9}, W_{10}, W_{11}, W_{12}$. A Relong substrate is adopted to support the antenna structure with a thickness of $0.7874 \mathrm{~mm}$. Its relative dielectric constant and loss tangent is 2.55 and 0.0009 , respectively. The serially connected solar cells are glued to the top of the substrate. Two metallic strips with the size of $L_{2}$ and $W_{2}$ are connected to the positive and negative poles of solar cells. The DC path and RF feeding structure are printed on the bottom of the substrate. Vertical strips are used to connect the top metallic strips and bottom DC path.

The radiation structure consists of five parallel patches with separation of $W_{3}$. Each patch has a size of $L_{1} \times W_{1}$, which consists of 8 solar cells and the proposed antenna includes a total of 40 solar cells. It is observed from Figs. 2(a) and 2(b) that four slots are formed by these solar cells and metallic strips. To stimulate the slot antenna, the aperture coupling method is adopted for the excitation. The feeding system is printed on the bottom of the substrate including four feeding strips, power dividers, and the transmission line connected to the SMA connector, as shown in Fig. 2(c). Based on the electromagnetic coupling mechanism, the DC can be blocked effectively, it can also realize a wideband impedance matching, as discussed in [23].

To collect the DC energy, the DC path is designed including the top metallic strips, the bottom strips with widths of $W_{11}$, and the bandstop filters. Instead of lumped inductor and capacitor $[24,25,26]$, a microstrip bandstop filter is introduced into the DC path to block the RF currents to reduce the insertion loss [27]. The microstrip filter structure is shown in Fig. 2(d). The simulated result shows that isolation of more than $10 \mathrm{~dB}$ can be obtained by the bandstop filter across the passband.

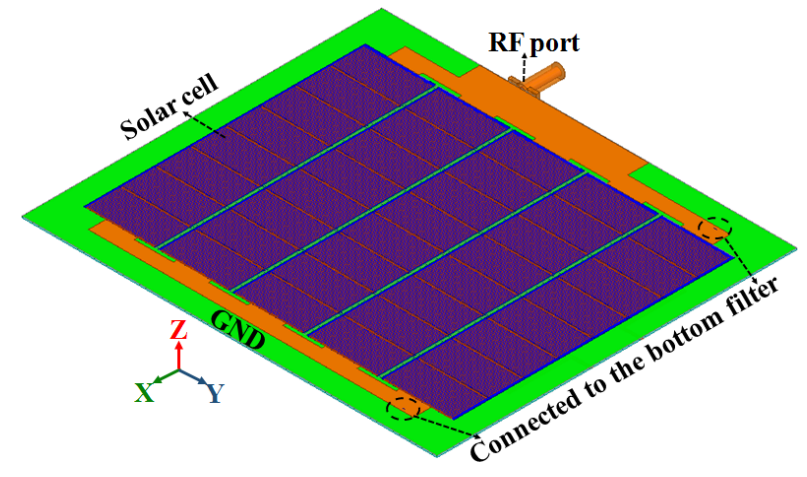

(a)

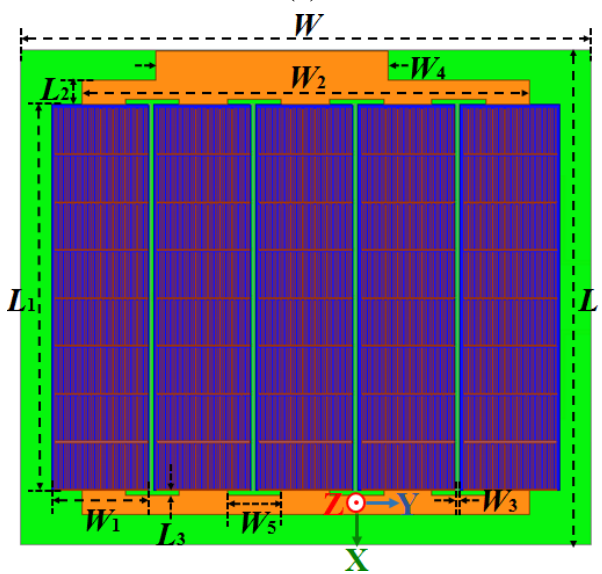

(b)

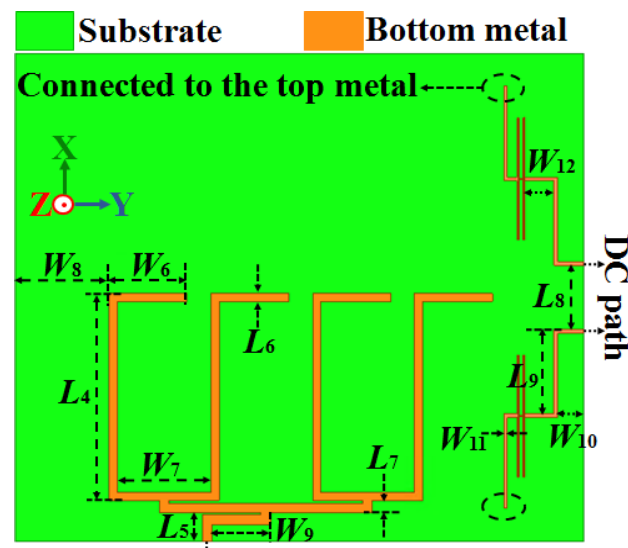

RF feeding strip

(c)

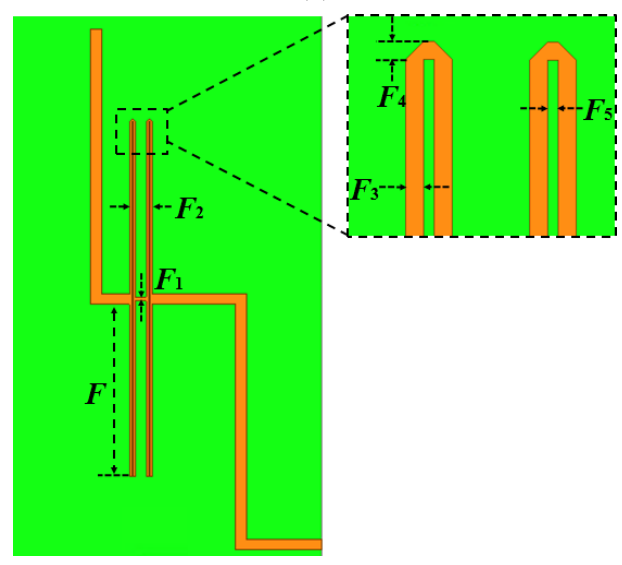

(d)

Fig. 2 Structure of the microstrip antenna integrated with solar cells: (a) 3D view, (b) top view, (c) bottom view, (d) filter. 
Table I Antenna structure parameter: (mm)

\begin{tabular}{c|c|c|c|c|c|c}
\hline Para. & $L$ & $L_{1}$ & $L_{2}$ & $L_{3}$ & $L_{4}$ & $L_{5}$ \\
\hline Value & 202.55 & 158.35 & 10 & 1 & 85.925 & 12 \\
\hline Para. & $L_{6}$ & $L_{7}$ & $L_{8}$ & $L_{9}$ & $W$ & $W_{1}$ \\
\hline Value & 3.3 & 5 & 29.85 & 39.25 & 233.68 & 40.8 \\
\hline Para. & $W_{2}$ & $W_{3}$ & $W_{4}$ & $W_{5}$ & $W_{6}$ & $W_{7}$ \\
\hline Value & 183 & 1 & 95 & 22 & 32 & 38.5 \\
\hline Para. & $W_{8}$ & $W_{9}$ & $W_{10}$ & $W_{11}$ & $W_{12}$ & $F$ \\
\hline Value & 37.55 & 24 & 10.75 & 1.5 & 11.9 & 24.49 \\
\hline Para. & $F_{1}$ & $F_{2}$ & $F_{3}$ & $F_{4}$ & $F_{5}$ & \\
\hline Value & 0.5 & 3.3 & 0.35 & 0.35 & 0.2 & \\
\hline
\end{tabular}

\section{Antenna analysis}

To investigate the working principle of the proposed slot antenna, the effective and instantaneous current distributions are plotted in Fig. 3. It is observed in Fig. 3(a) that most currents are distributed around the slot area. For each slot, there are four minimum current points along the edge of the slot. This can also be verified from the instantaneous current

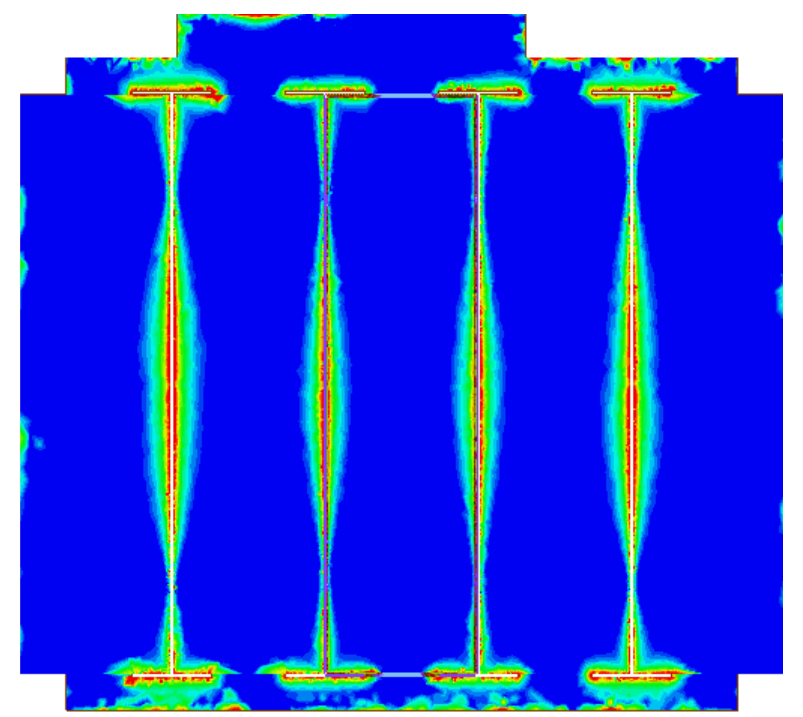

(a)

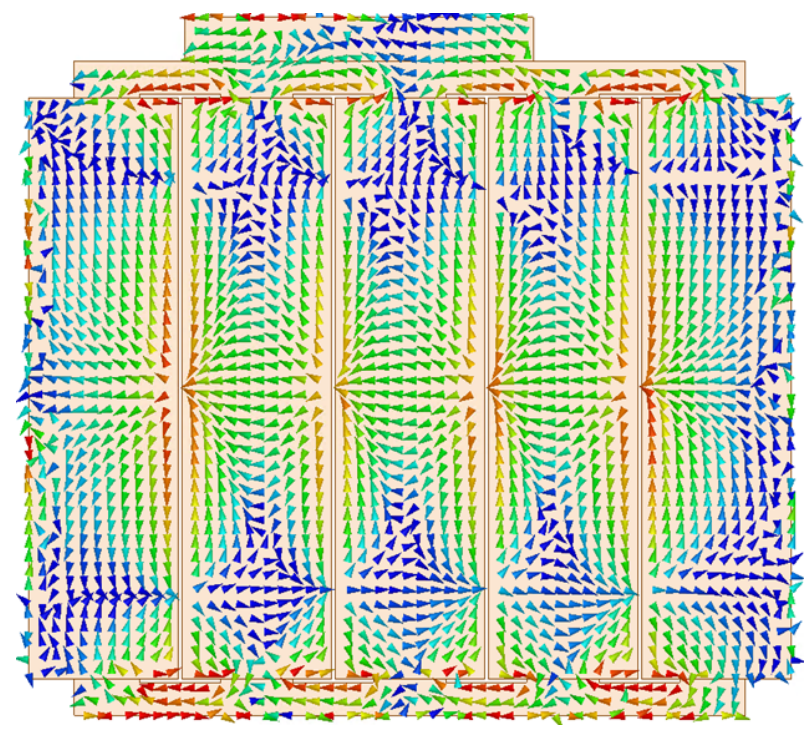

(b)

Fig. 3 Current distributions of the proposed antenna at $1.575 \mathrm{GHz}$ : (a) effective current distribution, (b) instantaneous current distribution. distribution in Fig. 3(b).

As these four I-shaped slots are stimulated by in-phase signals, they have the same current distributions. It is observed in Fig. 3(b) that the instantaneous current distribution of each slot contains four half-wavelength current distributions at $1.575 \mathrm{GHz}$. There are two half-wavelength current distributions at the center of each slot structure, which acts as the main radiation structure. The other two half-wavelength current distributions are at the top and bottom of the I-shaped slot, where the currents are in opposite directions and they have less effect on the radiation pattern. It can be concluded that the slot antenna is working at two-wavelength mode at $1.575 \mathrm{GHz}$.

The high-order mode can realize a larger aperture size with a higher antenna gain and more solar cells can be integrated to form the radiation structure, so the radiation performance is improved and its ability of DC power generation can be enhanced with a higher output voltage.

\section{Experiment verification}

To validate the proposed design, an antenna prototype is fabricated, as shown in Fig. 4. The software High-Frequency Structure Simulator (HFSS) is used to simulate the antenna performance. It is measured using a vector network analyzer and an anechoic chamber. The simulation and measurement results of $S$-parameter and gain are plotted in Figs. 5 and 6.

It is noticed in Fig. 5 that the measured $-10-\mathrm{dB}$ bandwidth is from 1.45 to $1.77 \mathrm{GHz}$ while the simulated $-10-\mathrm{dB}$ bandwidth is from 1.51 to $1.78 \mathrm{GHz}$. The target band at $1.575 \mathrm{GHz}$ has been fully covered. The measured gain at $1.575 \mathrm{GHz}$ is $6.6 \mathrm{dBi}$ while the simulated gain is $7.7 \mathrm{dBi}$. The measured peak gain is $7 \mathrm{dBi}$ at $1.63 \mathrm{GHz}$ Bidirectional radiation patterns have been achieved and the radiation patterns at $1.575 \mathrm{GHz}$ are plotted in Fig. 7. It is clear that the simulated and measured co-polarization results agree well with each other and the measured cross-polarization levels are below $-14 \mathrm{~dB}$.

It is also noticed that certain deviations exist between simulation and measurement, the reason is mainly due to the assembly errors. These solar cells are soldered and connected in series, then glued and fixed to the required

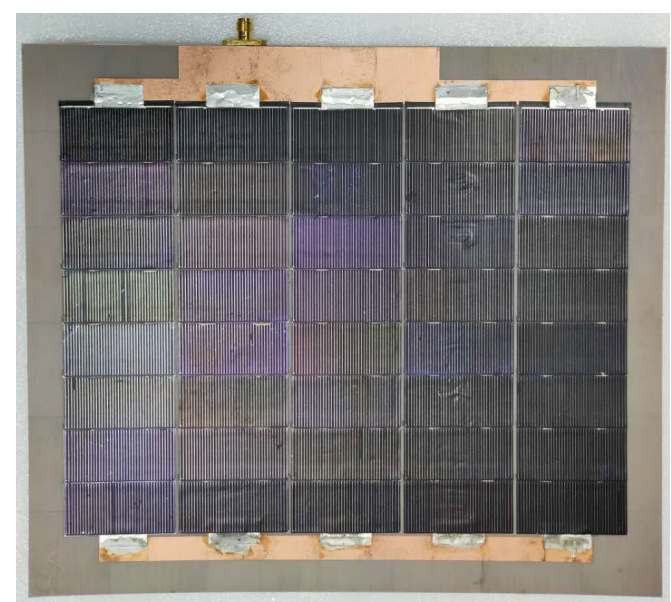

Fig. 4 The prototype of the proposed solar-cell antenna. 


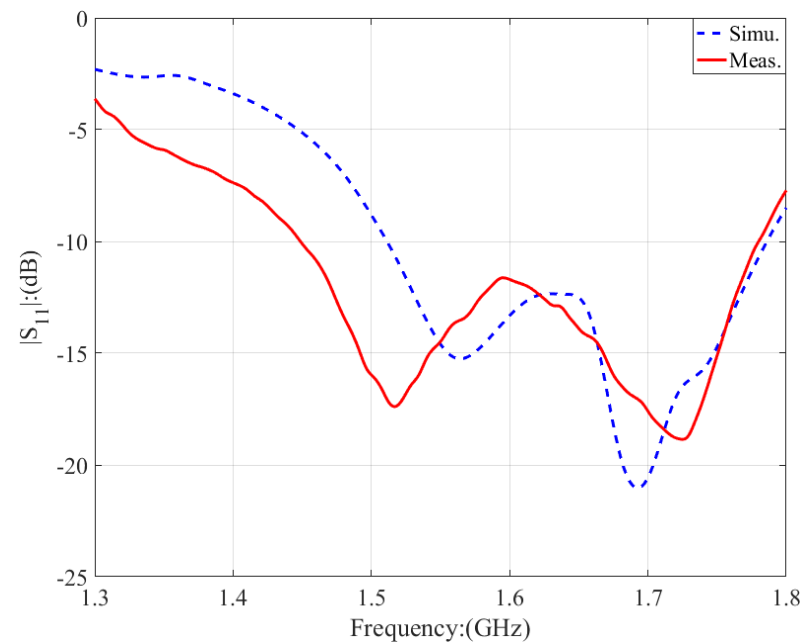

Fig. 5 The measurement and simulation results of $S$-parameters.

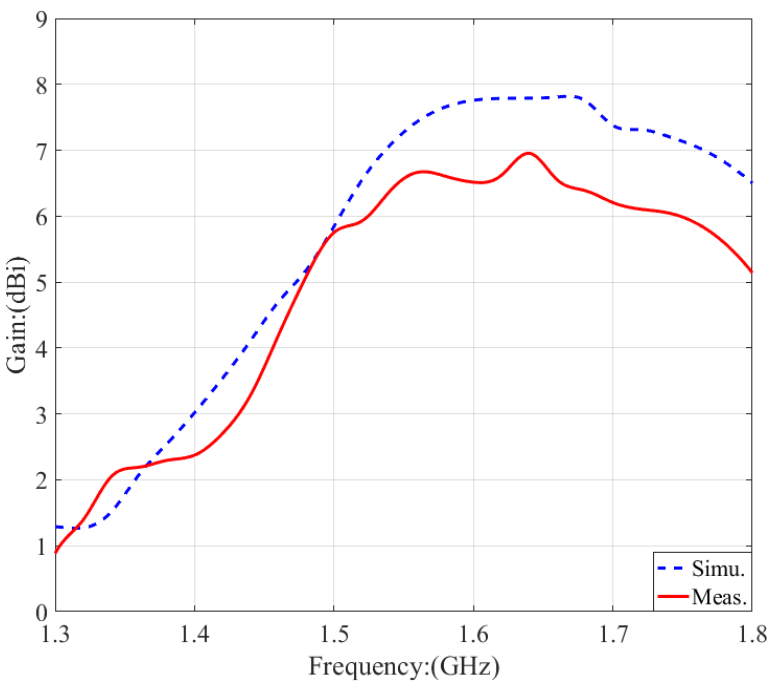

Fig. 6 The measurement and simulation results of gains.

position. All these procedures are conducted manually, so the assembly errors are inevitable and the measured gains are lower than the simulated results.

To further understand the proposed slot antenna, Table II shows the comparison between this work and some other antennas working at $1.575 \mathrm{GHz}$. A monopole antenna integrated with a single solar cell for IoT and wearable applications has been proposed in [18] with a relative bandwidth of $10 \%$ and a gain of $-10 \mathrm{dBi}$ at $1.575 \mathrm{GHz}$. To improve the antenna performance, an ultrawideband Vivaldi antenna was discussed in [19] with an end-fire radiation pattern by cutting an open slot on a single solar cell. To integrate more solar cells, 36 solar cells have been introduced into a planar antenna for GPS applications. However, the antenna gain is only $2 \mathrm{~dB}$. To augment the antenna gain, the proposed antenna integrated with 40 solar cells can realize a higher measured gain of $6.6 \mathrm{dBi}$ with a moderate bandwidth and coverage ratio of the solar cell over the total area.

\section{Optical experiment}

As a dual-function device, an optical experiment is con-

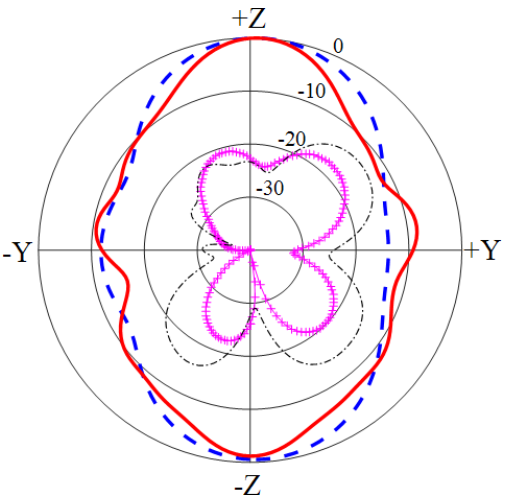

(a)

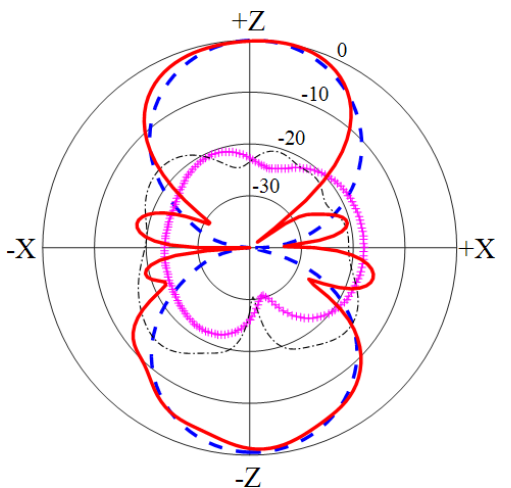

(b)

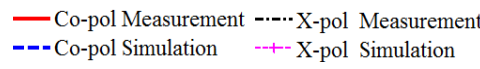

Fig. 7 The measured and simulated radiation patterns at $1.575 \mathrm{GHz}$ : (a) E-plane, (b) H-plane.

Table II Comparison of the proposed antenna with existing ISM solar-cell antenna designs

\begin{tabular}{c|c|c|c|c}
\hline Ref. & $\begin{array}{c}\text { Bandwidth at } \\
1.575 \mathrm{GHz} \\
(\%)\end{array}$ & $\begin{array}{c}\text { Peak } \\
\text { Gain } \\
(\mathrm{dB})\end{array}$ & $\begin{array}{c}\text { Radiation } \\
\text { Pattern }\end{array}$ & $\begin{array}{c}\text { Ratio of the } \\
\text { solar cell over } \\
\text { total area (\%) }\end{array}$ \\
\hline$[18]$ & 10 & -10 & Omnidirection & 35 \\
\hline$[19]$ & 88 & 2.5 & Endfire & 94 \\
\hline$[21]$ & 47 & 2 & Bidirection & 70 \\
\hline $\begin{array}{c}\text { This } \\
\text { work }\end{array}$ & 19.9 & 6.6 & Bidirection & 68 \\
\hline
\end{tabular}

ducted to test its ability of DC power generation, as shown in Fig. 8. The solar cells of the proposed slot antenna are illuminated by a $35-\mathrm{W}$ lamp, which can be treated as the battery of the serially connected circuit. A variable resistor acts as the load of the circuit. Ammeter and voltmeter are adopted to measure the current and voltage of the resistive load when the solar cells are illuminated at different distances. The distance between the lamp and solar cells is set to be $150 \mathrm{~mm}$ and $300 \mathrm{~mm}$, respectively.

To evaluate the ability of DC generation, the value of the load varies between $0 \Omega$ to $10000 \Omega$, the current and voltage of the load are measured and the output power of the solar cells is calculated and plotted in Fig. 9. It is observed in Fig. 9 that the output power depends on the illumination distance. Higher output power can be achieved when the solar cells are close to the lamp. The maximum output is $0.063 \mathrm{~W}$ when the illumination distance is $150 \mathrm{~mm}$. The output power begins to decrease when the illumination distance increases. The peak output power is $0.024 \mathrm{~W}$ while 


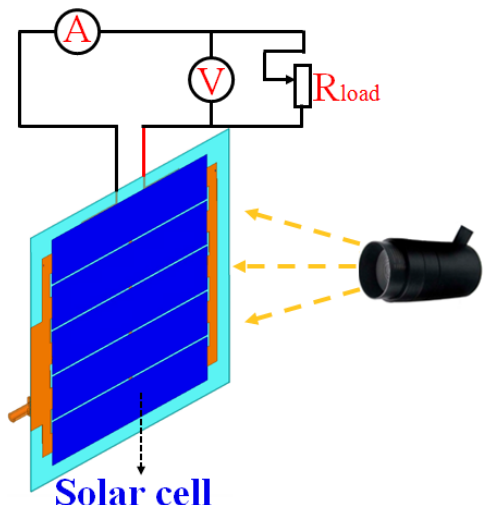

Fig. 8 Diagram of the optical experiment setup.

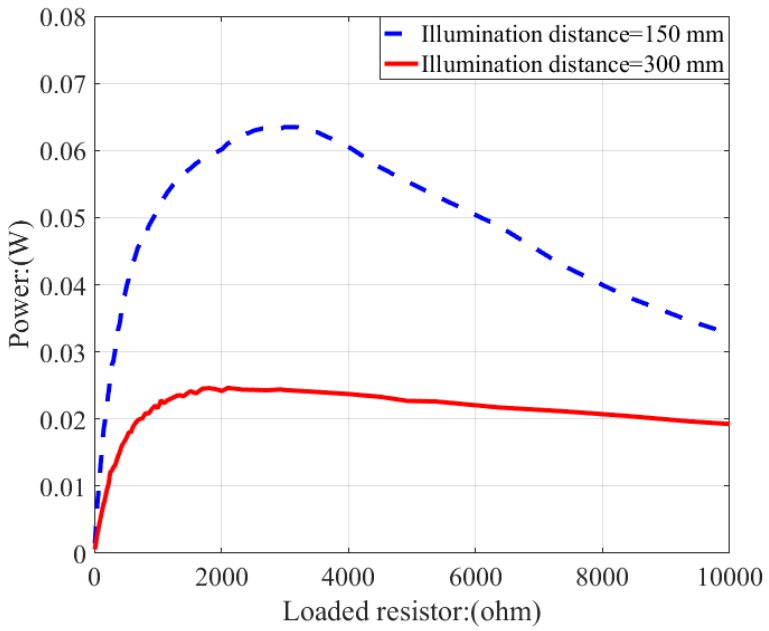

Fig. 9 The calculated output power against the load resistance.

the illumination distance is $300 \mathrm{~mm}$. Compared with the results in $[28,29,30]$, the ability of DC power generation has been enhanced effectively because more solar cells are employed to form the slot antenna.

\section{Conclusion}

A dual-function slot antenna integrated with 40 solar cells is proposed for the global navigation satellite systems at 1.575 GHz. The antenna is with a high-order mode and more solar cells can be introduced into the radiation structure. A relative bandwidth of $19.9 \%$ has been achieved from 1.45 to $1.77 \mathrm{GHz}$. Bidirectional radiation performances are obtained with a measured gain of $6.6 \mathrm{dBi}$. The performance of DC power generation has been improved compared with previous works. Because of these favorable characteristics, this dual-function solar-cell slot antenna should find widespread applications for future global navigation systems.

\section{Acknowledgments}

This work was supported in part by the National Natural Science Foundation of China (Grant No. 61701339), in part by the National Key Research and Development Program of China (Nano Science and Technology Project, no. 2016YFA0202200), and in part by the AoShan Talents Cultivation Program Supported by Qingdao National Lab- oratory for Marine Science and Technology under Grant No. 2017ASTCP-OS03, and in part by Guangdong Yangfan Plans to Introduce Innovative Entrepreneurship Team Project. No. 2016YT04G420.

\section{References}

[1] Y.-J. Kim, et al:: “A 5.4mW concurrent low noise CMOS LNA for L1L5 GPS application," IEICE Electron. Express 6 (2009) 14 (DOI: 10.1587/elex.6.14).

[2] Y. Wang, et al.: "A RF CMOS GNSS receiver with a passive mixer for GPS L1/Galileo E1/Compass B1 band," IEICE Electron. Express 15 (2018) 1 (DOI: 10.1587/elex.15.20180551).

[3] Y. Yang, et al.: "An architecture design for anti-jamming circuit with low power and low area cost in high-precision GNSS receiver chip," IEICE Electron. Express 16 (2019) 1 (DOI: 10.1587/elex. 16.20190179).

[4] I. Jo, et al.: "Design of triple-band CMOS GPS receiver RF frontend," IEICE Electron. Express 10 (2013) 1 (DOI: 10.1587/elex. 10.20130126).

[5] Y. Yin, et al.: "The design of large image rejection and wideband CMOS active polyphase filter for BeiDou RF receiver," IEICE Electron. Express 17 (2020) 12 (DOI: 10.1587/elex.17.20200110).

[6] G. Jin, et al.: "A stable and two-step settling digital controlled AGC loop for GNSS receiver," IEICE Electron. Express 11 (2014) 1 (DOI: 10.1587/elex.11.20140738).

[7] M. Zhao and J. Liao: "A compact low power current-mode LNAmixer for RF receiver," IEICE Electron. Express 14 (2017) 1 (DOI: 10.1587/elex.14.20170773).

[8] H. Morimura, et al.: "Ultra-low-power circuit techniques for mmsize wireless sensor nodes with energy harvesting," IEICE Electron. Express 11 (2014) 1 (DOI: 10.1587/elex.11.20142009).

[9] M. Akbari, et al.: "Internal multiband PIFA antenna for GPS/DCS/ PCS/UMTS/WLAN operation in the mobile device," IEICE Electron. Express 6 (2009) 1752 (DOI: 10.1587/elex.6.1752).

[10] C. Li, et al.: "A dual-band circularly polarized antenna with wide half HPBWs for CNSS applications," IEICE Electron. Express 15 (2018) 1 (DOI: 10.1587/elex.15.20180409).

[11] M.M. Rabie, et al:: "Meshed conductor and meshed substrate GPS L1 band microstrip antenna for cubesat applications," NRSC (2018) 55 (DOI: 10.1109/NRSC.2018.8354359).

[12] M. Matsunaga, et al.: "A cross shaped spiral antenna radiating omnidirectional circularly and linearly polarized waves," IEICE Electron. Express 9 (2012) 256 (DOI: 10.1587/elex.9.256).

[13] H. Kang and S. Lim: "Electrically small dual-band substrateintegrated-waveguide antenna with fixed low-frequency and tunable high-frequency bands," IEICE Electron. Express 11 (2014) 1 (DOI: 10.1587/elex.11.20140007).

[14] Y.-C. Kan, et al:: "A GPS anchor node for outdoor wireless sensor network applications," RFIT (2009) 40 (DOI: 10.1109/RFIT.2009. 5383734).

[15] S. Vaccaro, et al.: "In-flight experiment for combined planar antennas and solar cells (SOLANT)," IET Microw. Antennas Propat. 3 (2009) 1279 (DOI: 10.1049/iet-map.2008.0410).

[16] M.J.R. Ons, et al.: "Emitter-wrap-through photovoltaic dipole antenna with solar concentrator," Electron. Lett. 45 (2009) 241 (DOI: org/10.1049/el:20093617).

[17] N. Henze, et al.: "Application of photovoltaic solar cells in planar antenna structures," Twelfth International Conference on Antennas and Propagation (ICAP 2003) (2003) 731 (DOI: 10.1049/cp:20030180).

[18] A. Vorobyov, et al.: "Solar cell antenna for IoT and wearble applications," EUCAP (2019).

[19] O. O'Conchubhair, et al:: "Amorphous silicon solar Vivaldi antenna," IEEE Antennas Wireless Propag. Lett. 15 (2016) 893 (DOI: 10.1109/LAWP.2015.2479189).

[20] N. Henze, et al.: "Investigation of planar antennas with photovoltaic solar cells for mobile communications," PIMRC (2004) 622 (DOI: 10.1109/PIMRC.2004.1370945).

[21] N. Henze, et al.: "GPS patch antenna with photovoltaic solar cells for vehicular applications," VETECF (2003) 50 (DOI: 10.1109/VETECF. 2003.1284976). 
[22] A.S. Kumar and S. Sundaravadivelu: "An efficient design of solar cell antenna for mobile and vehicular applications," GHTY (2011) (DOI: 10.1109/GHTC.2011.14).

[23] R.L. Li, et al.: "Equivalent-circuit analysis of a broadband printed dipole with adjusted integrated balun and array for base station applications," IEEE Trans. Antennas Propag. 57 (2009) 2180 (DOI: 10.1109/TAP.2009.2021967).

[24] Y. Li, et al.: "A compact hepta-band loop-inverted F reconfigurable antenna for mobile phone," IEEE Trans. Antennas Propag. 60 (2012) 389 (DOI: 10.1109/TAP.2011.2167949).

[25] Y. Li, et al.: "A switchable matching circuit for compact wideband antenna designs," IEEE Trans. Antennas Propag. 58 (2010) 3450 (DOI: 10.1109/TAP.2010.2071345).

[26] Y. Li, et al.: "Polarization reconfigurable slot antenna with a novel compact CPW-to-slotline transition for WLAN application," IEEE Antennas Wireless Propag. Lett. 9 (2010) 252 (DOI: 10.1109/ LAWP.2010.2046006).

[27] S. Luo, et al.: "Stopband-expanded low-pass filters using microstrip coupled-line hairpin units," IEEE Antennas Wireless Compon. Lett. 18 (2008) 506 (DOI: 10.1109/LMWC.2008.2001004).

[28] W. An, et al.: "A Ka-band reflectarray antenna integrated with solar cells," IEEE Trans. Antennas Propag. 62 (2014) 5539 (DOI: 10.1109/TAP.2014.2354424).

[29] W. An, et al.: "A Ka-band high-efficiency transparent reflectarray antenna integrated with solar cells," IEEE Access 6 (2018) 60843 (DOI: 10.1109/ACCESS.2018.2875359).

[30] W. An, et al.: "A wideband dual-function solar cell dipole antenna for both energy harvesting and wireless communications," IEEE Trans. Antennas Propag. (2020) 1 (DOI: 10.1109/TAP.2020.3005250). 